\title{
Knowledge of Otic Barotrauma among Air Travelers in Sialkot, Pakistan
}

\author{
Muhammad Saeed Razi ${ }^{1}$, Saleh Muhammad ${ }^{2}$, Asif Javed ${ }^{3}$, Javaid Riaz Qureshi ${ }^{4}$, Miss Mahnoor ${ }^{5}$, Mujahid \\ Hussain $^{6}$ \\ ${ }^{1}$ Assistant Professor, Department of ENT, Sialkot Medical College, Sialkot, Pakistan \\ ${ }^{2}$ Associate Professor, Department of Medicine, Sialkot Medical College, Sialkot, Pakistan \\ ${ }^{3}$ Assistant Professor, Department of Medicine, M. Islam Medical College, Gujranwala, Pakistan \\ ${ }^{4}$ Assistant Professor, Department of ENT, Khawaja M Safdar Medical College, Sialkot, Pakistan \\ ${ }^{5}$ Final year MBBS student, Federal Medical and Dental College, Islamabad Pakistan \\ ${ }^{6}$ Assistant Professor, Department of Biology, FG Degree College (M), Kharian Cantt., Pakistan
}

\begin{abstract}
A B S TR ACT
Background: Otic barotrauma (OBT) is defined as traumatic inflammation in human middle ear that occurs at the time of avian drop. However, it can be avoided using its adequate knowledge. The objective of present study was to evaluate the knowledge of the trauma among air travelers in Sialkot city of Punjab, Pakistan.

Material and Methods: This cross-sectional study enlisted male adult International air travelers ( $=50)$ from Sialkot city, Pakistan between November 2018 and April 2019 using purposive sampling technique. A specially developed questionnaire (Cronbach's alpha $=.82$ ) having 12 close-ended items on barotrauma (total possible score 12) was administered to the participants at their home. Level of knowledge was categorized as inadequate (score 0-6), moderate (7-9) and adequate (10-12). Pearson's chi-squared test was used to see the association between adequate knowledge on the OBT and sociodemographic variables using a P-value $<.05$ as statistically significant.

Results: Mean age of the participants was $47.60 \pm 9.9$ years. Most of them $(n=36 ; 72 \%)$ travelled for work reason. Almost all i.e. 46 (92\%) gave correctresponse against item 1 (information provider about air trauma) and 12 (treatment of otic barotrauma) of the administered questionnaire. The rate of adequate knowledge on OBT was found to be higher among those having more than two-time travelling experience $(82.9 \%, \mathrm{P}=.02)$. However, there was no significant difference in knowledge of the barotrauma between people having less than or more than 12 years of science education $(P=.59)$. All the business tourists $(n=5)$ had adequate knowledge of barotrauma followed by jobbers $(n=25)$ and pilgrims ( $n=3)$, respectively.

Conclusions: Business tourists have adequate knowledge on otic barotrauma associated with air travel than jobbers or Hajj/Umrah pilgrims.

Key words: Air travel agents, International air travelers, Otic barotrauma, Pakistan.
\end{abstract}

\begin{tabular}{|c|c|c|}
\hline Authors' Contribution: & Correspondence: & Article info: \\
\hline $\begin{array}{l}{ }^{1} \text { Conception; Literature research; } \\
\text { manuscript design and drafting; }{ }^{2,3} \text { Critical } \\
\text { analysis and manuscript review; }{ }^{4-6} \text { Data } \\
\text { analysis; Manuscript Editing. }\end{array}$ & $\begin{array}{l}\text { Mujahid Hussain } \\
\text { Email:hmujahid64@yahoo.com }\end{array}$ & $\begin{array}{l}\text { Received: October } 11,20 \\
\text { Accepted: February 22, } 2\end{array}$ \\
\hline
\end{tabular}

Knowledge of Otic Barotrauma among Air Travelers in Sialkot,
Dental Coll. 2021; 10(1):37-43. Doi: 10.35787/jimdc.v10i1.433 


\section{Introduction}

Otic barotrauma (OBT) also called acute aerotitis media $^{1}$ is defined as traumatic inflammation in middle ear (ME) followed by hearing discomfort on changes in atmospheric pressure inside the cabin of an airplane. At the time of airplane descent, atmospheric pressure increments in the cabin with a reduction in the middle ear (ME). Ultimately, a pressure difference of $60 \mathrm{mmHg}$ approaches which hinders the eustachian tube (ET). The blockage prevents passive entry of the air in ME and causes hearing inconvenience. Usually, the issue settles by ear maneuvering. However, chances of severe $\mathrm{OBT}^{2,3}$ increases on further increase in the difference ( $\geq 90 \mathrm{~mm}$ of $\mathrm{Hg}$ ). This condition may lead to hyperemia of tympanic membrane or hemorrhagein ME.

Like colonic barotrauma, ${ }^{4}$ OBT warrants appropriate knowledge on prevention and treatment. Knowledge-based practice of precautionary measures e.g., swallowing ensures equalization of pressure on both sides of the tympanic membrane. This facilitates re-entry of the air in ET for hearing. ${ }^{3,5}$ Similarly, anti-allergy ${ }^{2,6}$ or topical nasal/systemic decongestant(s) prophylaxis is advised for the pertinent patients. In case of mild trauma, practice of Valsalva's maneuver is effective. ${ }^{7}$

Knowledge of a problem is gauged in its vulnerable/affected population using easy to response study tool e.g., questionnaire. Knowledge of an infectious disease among students, ${ }^{8}$ or OBT among air travelers can be cited in this context. In contrast to Australia, ${ }^{9}$ researchers have no access to the respondents (air travelers) at airport domains of Pakistan such as waiting lounge on account of legitimate boundaries. So, one has to recruit the subjects from civilian residential areas to know their unpleasant experiences in air traveling.
Online published literature is available on assessing the knowledge of the problem among flight crew members or air travelers at airport domains. ${ }^{1,3,7,10}$ However, there is no precedence of recruiting air travelers from civil residential areas especially in Pakistan. To address the gap, present study was designed. The objective of the study was to evaluate the knowledge on OBT among air travelers in Sialkot city of Punjab, Pakistan. It will not only help civil aviation authorities in revising travelers' guide but also air travel agents in reviewing information package for clients.

\section{Material and Methods}

This cross-sectional study was conducted between November, 2018 and April, 2019 in Sialkot city, Pakistan after getting permission from the Ethics Committee of Rachna Hospital, Sialkot, Pakistan. Adult male residents of Sialkot city $(n=50)$, who had at least 12 years of academic education in science subjects and minimal two-times experience of international air travel, were included in the study. The purpose of travel might vary from business, to job, Hajj/Umrah, medical treatment or recreational trip. The eligible individuals were recruited using chain referral sampling technique. The final enrollment was based on positive participation consent. Those who had any severe physical or mental problems were excluded.

A total of 492 air travelers (i.e., accessible population) were documented in a computergenerated table from administrative jurisdiction of Sialkot city. Whereas, sample size was found to be 50 (approximately $10 \%$ of the accessible population) following principles of sampling ${ }^{11,12}$ for pilot study on clinical issues. The 50 subjects were recruited from the accessible population using purposive sampling technique. 
During questionnaire development, a team of language (English) specialists and practicing psychologists having enough knowledge on OBT set candidate questions in the questionnaire. The tool was administered to 15 air travelers (first focus group) for acceptability of the questions. The response-based revised version was given to the second group ( $n=15$ ) while next revised version was administered to the same-sized third group. So, a total of 45 individuals (selected from the accessible population) participated in the practice. However, these participants were not considered for giving responses in the present pilot study. After the three rounds, the questionnaire was subjected to techniques of development including reliability test (Cronbach's alpha $=.82$ ). At the end, there was an instrument with 12 close-ended items. Item 1-4 (Section-A) were on general information while 5-12 (Section-B) were related to cause, predictors, prevention and treatment of OBT. Each item was followed by four response options. One mark was awarded if responder ticked the correct option against an item otherwise zero; hence, total possible scores were equal to 12 . The degrees of knowledge were categorized as inadequate (0-6), moderately adequate (7-9) and adequate (score: 10-12) knowledge.

Nominal and continuous data were processed for percentage and mean values, separately. The association between adequate knowledge on OBT and sociodemographic variables was seen using Pearson's Chi-squared test in SPSS software version 25.0. In the test, a $P$-value less than .05 was taken as statistically significant.

\section{Results}

All the 50 study subjects i.e., international air travelers, gave complete responses in the study tool for assessment of knowledge on OBT (response rate $=100 \%$ ). Mean age of the participants was $47.60 \pm$ 9.9 years with $56 \%(n=28)$ having more than 12 years of science education, $70 \%(n=35)$ with more than two-time experience of international air travel and $90 \%(n=45)$ obtained direct information from the travel agent. Similarly, most of them ( $n=36 ; 72 \%)$ travelled for ex-Pakistan job. Others traveled for Hajj/ Umrah or business visits. However, not a single case of air travel with the purpose of medical treatment or recreational trip(s) was recorded.

Table I shows responses of subjects against each of the 12 items in the survey tool. Forty-six (92\%) subjects marked correct option against item No. 1 on OBT-related information providing source in the administered questionnaire. The same rate (92\%) of correct answers was also found against item No. 12 on consequences of OBT. However, knowledge on medical insurance dealing agency (item No. 4) was evidently low with only 19 participants (38\%) holding airline as the responsible party.

Table II show association of the adequate level of the knowledge on OBT with demographic variables. The rate of adequate knowledge on OBT (score: 9-12 out of total possible 12) was found to be higher among travelers with more than two-time travelling experience $(82.9 \%, P=.02)$.-Adequate knowledge showed insignificant association with age of the subjects or practice of direct information seeking from air travel agent $(P=.30)$.

Figure 1 depict adequate knowledge in various categories of the participants in the study. In business tourists, the rate of the knowledge was $80 \%$ in Section A (item: 1-4 pertaining to general knowledge on OBT) and $100 \%$ in Section B (item: 5 12 on OBT specific knowledge) of the questionnaire. The pilgrims or jobbers likewise had higher rate of information in section $B$ as compared to $A$. 


\begin{tabular}{|c|c|c|c|}
\hline S. No & Items & Response options & $\%(n)$ \\
\hline \multirow{4}{*}{1} & \multirow{4}{*}{$\begin{array}{l}\text { This person/site informs about } \\
\text { the incidence of trauma: }\end{array}$} & A - Air traveling agent & $8(4)$ \\
\hline & & B - Waiting lounge for air passengers & - \\
\hline & & $\mathrm{C}-$ Air attendant in the plane & - \\
\hline & & D-None of the above & $92(46)$ \\
\hline \multirow{4}{*}{2} & \multirow{4}{*}{$\begin{array}{l}\text { GoP have never ever launched } \\
\text { a public awareness campaign } \\
\text { on: }\end{array}$} & A - Air traveling ethics & $10(5)$ \\
\hline & & B - Banned items in air traveling & $2(1)$ \\
\hline & & C - Management of health issues in a flight & $84(42)$ \\
\hline & & D - Rate of air fare & $4(2)$ \\
\hline \multirow{4}{*}{3} & \multirow{4}{*}{$\begin{array}{l}\text { Select the most efficient media } \\
\text { for educating the youth about } \\
\text { the trauma: }\end{array}$} & A - Newspaper (e.g., through columns) & - \\
\hline & & B - Television (e.g., through drama) & $4(2)$ \\
\hline & & C-Social media (e.g., Facebook) & $82(41)$ \\
\hline & & D - Pana Flexes in main chowks of each city & $14(7)$ \\
\hline \multirow{4}{*}{4} & \multirow{4}{*}{$\begin{array}{l}\text { Claim amount of medical } \\
\text { insurance on perforation in } \\
\text { the air drum (after aerotitis) } \\
\text { can be obtained from: }\end{array}$} & A - Air travel agent & $20(10)$ \\
\hline & & B - Concerned air line & 38 (19) \\
\hline & & C-Government (to which airline belongs) & $10(5)$ \\
\hline & & D - Civil Aviation Authority & $32(16)$ \\
\hline \multirow{4}{*}{5} & \multirow{4}{*}{ Otic barotrauma is a: } & A - Sign of psychological problem & $2(1)$ \\
\hline & & B - Result of physical tiredness & $4(2)$ \\
\hline & & C-Indicator of decrease of air pressure within ear & $74(37)$ \\
\hline & & D- Result of technical mishandling by aircrew & $20(10)$ \\
\hline \multirow{4}{*}{6} & \multirow{4}{*}{ Barotrauma generally occurs: } & A-Before taking off the plane & - \\
\hline & & B - During taking off & $20(10)$ \\
\hline & & $\mathrm{C}-$ When the plane is at its maximum height & $2(1)$ \\
\hline & & D - On landing & $78(39)$ \\
\hline \multirow{4}{*}{7} & \multirow{4}{*}{$\begin{array}{l}\text { A person with following } \\
\text { problem is under high threat } \\
\text { of barotrauma: }\end{array}$} & A-Obesity & $12(6)$ \\
\hline & & B - High blood pressure & $8(4)$ \\
\hline & & C-Dust allergy & $76(38)$ \\
\hline & & D - Mental depression & $4(2)$ \\
\hline \multirow{4}{*}{8} & \multirow{4}{*}{ Select a factor for barotrauma: } & A - Position of the seat in the cabin & $10(5)$ \\
\hline & & B - Altitude of the plane & $86(43)$ \\
\hline & & C-Shape of the cabin & - \\
\hline & & D - Susceptibility of the passenger to aerotitis & $4(2)$ \\
\hline \multirow{4}{*}{9} & \multirow{4}{*}{$\begin{array}{l}\text { A person with following habit } \\
\text { is under high threat of } \\
\text { barotrauma: }\end{array}$} & A - Drinking alcohol & $10(5)$ \\
\hline & & B - Smoking tobacco & $82(41)$ \\
\hline & & $\mathrm{C}$ - Inhaling narcotics & $8(4)$ \\
\hline & & D-Dieting & - \\
\hline \multirow{4}{*}{10} & \multirow{4}{*}{$\begin{array}{l}\text { Which practice cannot help in } \\
\text { protecting from otic } \\
\text { barotrauma? }\end{array}$} & A-Sleeping & 78 (39) \\
\hline & & B-Swallowing of food & $10(5)$ \\
\hline & & $\mathrm{C}-$ Use of chew gum & $8(4)$ \\
\hline & & D - Artificial yawning (opening of mouth) & $4(2)$ \\
\hline \multirow{4}{*}{11} & \multirow{4}{*}{$\begin{array}{l}\text { Severe prolonged barotrauma } \\
\text { needs help of a: }\end{array}$} & A - Medical specialist & $22(11)$ \\
\hline & & B - ENT specialist & $76(38)$ \\
\hline & & C-Allergy specialist & - \\
\hline & & D-Psychiatrist & $2(1)$ \\
\hline \multirow{4}{*}{12} & & A - Lasts for some hours and recovers itself & $2(1)$ \\
\hline & Ilcually otic harotrauma. & B - Finishes on mild ear fingering & $92(46)$ \\
\hline & 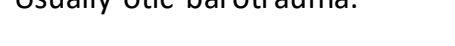 & $\mathrm{C}-$ Results in hole in the air drum & $6(3)$ \\
\hline & & D - Hits other ear problems & - \\
\hline
\end{tabular}

Correct options and relevant data are in bold letters; GoP - Government of Pakistan 


\begin{tabular}{|c|c|c|c|}
\hline Demographic Variables & Adequate knowledge \% (n) & $x^{2}$ value & $P$-value \\
\hline \multicolumn{2}{|l|}{ Age (years) } & \multirow{3}{*}{.734} & \multirow{3}{*}{.40} \\
\hline$\leq 48^{*}$ & $67.7(21)$ & & \\
\hline$>48$ & $78.9(15)$ & & \\
\hline \multicolumn{2}{|l|}{ Science education (years) } & \multirow{3}{*}{.284} & \multirow{3}{*}{.59} \\
\hline 12 & $68.2(15)$ & & \\
\hline$>12$ & $75.0(21)$ & & \\
\hline \multicolumn{2}{|l|}{ Experience of air travel } & \multirow{3}{*}{-} & \multirow{3}{*}{$.02 * *$} \\
\hline 2-times & $46.7(7)$ & & \\
\hline$>2$-times & $82.9(29)$ & & \\
\hline \multicolumn{2}{|c|}{$\begin{array}{l}\text { Practice of direct information seeking from } \\
\text { air travel agent }\end{array}$} & \multirow{3}{*}{-} & \multirow{3}{*}{.30} \\
\hline No & $100(5)$ & & \\
\hline Yes & $68.9(31)$ & & \\
\hline
\end{tabular}

*Arithmetic mean of age; ** Exact significant two sided; $x^{2}$-Chi-square

$P$-value $<.05$ was considered as statistically significant.

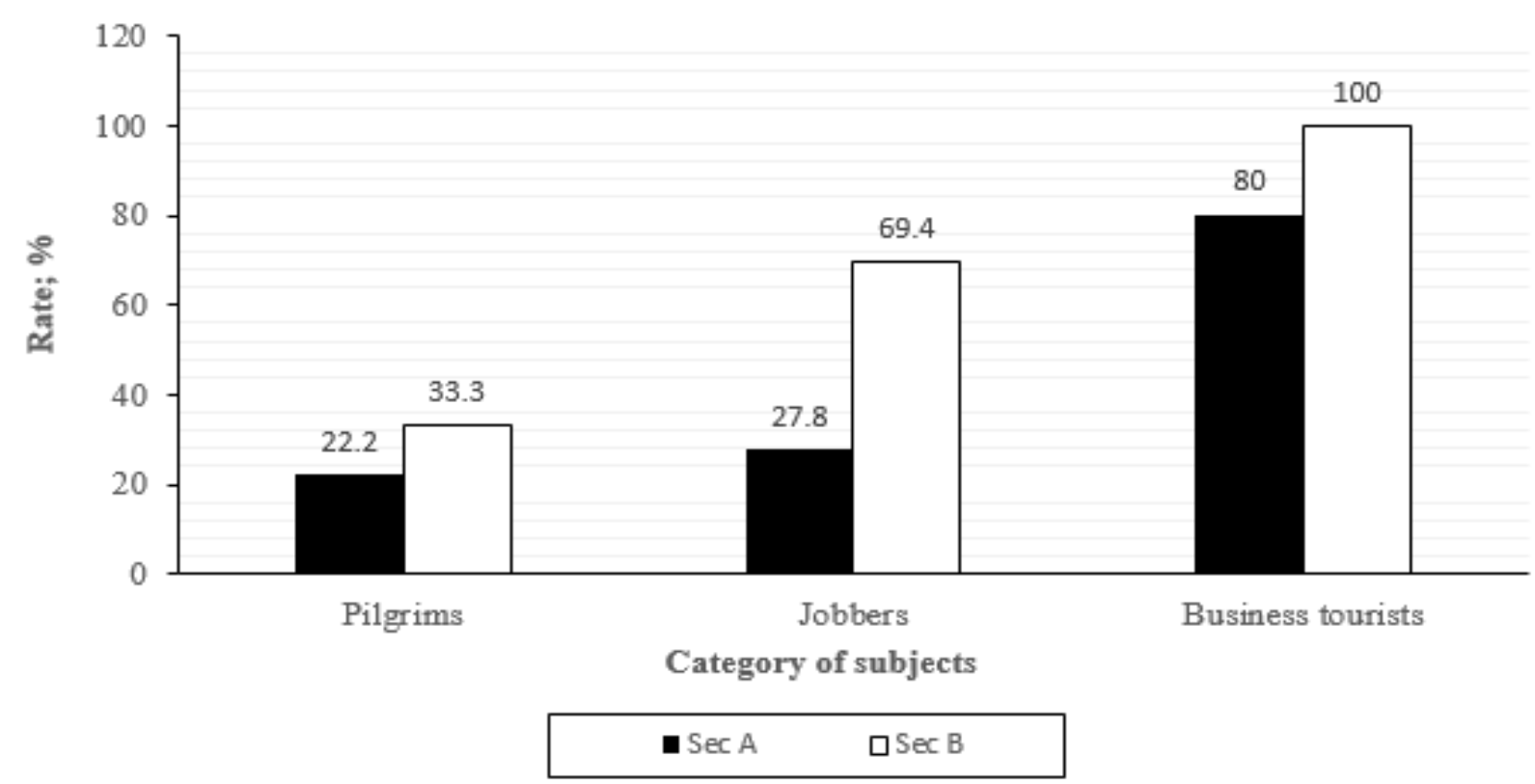

Figure 1: Adequate knowledge against three categories of the subjects (Pilgrims = 9, jobbers $=36$, and tourists $=5$ ) .

\section{Discussion}

Like Navy divers, air travelers are vulnerable to OBT. ${ }^{10,13,14}$ So, appropriate knowledge pertaining to barotrauma is essential for the travelers to avoid any complication. They can be accessed at the airport or home for assessment of the knowledge. In our study, $100 \%$ ( $n=50$ ) response rate reflects enthusiasm on part of the air travelers to participate in recording their responses candidly and with openness. ${ }^{15}$ Similarly, comfortable feelings exist in 
patients of pulmonary barotrauma in the clinical settings. ${ }^{16}$

Adequate knowledge (AK) on OBT among older subjects ( $78.9 \%$ in $>48$ versus $67.2 \%$ in $<48$ years) is in line with the findings of a similar questionnairebased survey on 15-72 years old air travelers at two UK airports. ${ }^{3}$ Knowledge in a particular area increases with advancing age. ${ }^{15}$ Similarly, travelers' awareness about prevention of OBT is agedependent as spending more years in acquiring scientific academic education clarifies the scientific concepts. It was observed that educated study subjects had comparatively higher rate of adequate knowledge (AK) on barotrauma (75\%), thus providing a physical demonstration of this education-consciousness coupling. Significantly higher AK rate (. 82.9\%) after more than two travel experiences is the result of experience - knowledge interactivity, ${ }^{8}$ indicating that experience enhances knowledge, cyclically. Lower AK rate in information seekers from the travel agents contradicts a widely accepted perception that frequent contact with the agents enhances the level of knowledge in the passengers, especially of physically/mentally disabled categories. ${ }^{17}$

In KAP (knowledge-attitude-practice), the knowledge and practice influence each other in a cyclic pattern. ${ }^{8,18,19}$ It is general practice of the air travelers to seek OBT related information from the traveling agent(s). This is why substantially higher numbers of subjects (46 of 50) opted for the correct option against item No.1 of the study tool. However, correct response on OBT-based insurance by just 19 people reflects general unawareness towards such essential matters. Unfortunately, general insurance policies have no evident space in Pakistan just like Addis Ababa, ${ }^{20}$ Ethiopia. High rate of correct response for item 12 (i.e., simple ear fingering resolves mild OBT) indicates adequate knowledge of the passengers regarding the unpleasant episode. Fingering is an appropriate alternate to complex
Valsalva's maneuver (a moderately forceful attempt of exhalation against a closed airway) at public place, provided there is no ENT infections. ${ }^{1,6,7,21,22}$

Adequate level of knowledge in all the business tourists might be due to their interest in being updated on OBT through internet facility, ${ }^{23}$ literature survey, and peer to peer discussions. Similarly, their strong socioeconomic background-derived trends might be responsible for $A K$ on $O B T$, just like better reading ability in a child ${ }^{24}$ of this class. Pilgrims and foreign jobbers lack this dimension and have inadequate knowledge on the OBT.

Inclusion of wide range of air passengers, their levels of knowledge on otic barotrauma, and emergence of predictors for the inadequate knowledge mark the strength of the present work. However, the study cannot be generalized due to bias related to a small sample size.

\section{Conclusion}

The higher rate of adequate level of knowledge on OBT was seen in business tourists followed by overseas jobbers and Hajj/Umrah pilgrims.

\section{References}

1. Fyntanakii Q, Alevitsovitis G, Angelakis L, Moutevelis V. Acute barotitis media in flight: Pathophysiology, symptoms, prevention, treatment. Balkan Mil Med Rev. 2013; 16(1): 50-5.

2. Mirza S, Richardson H. Otic barotrauma from air travel. J Laryngol Otol. 2005; 119(5): 366-70.

3. Mitchell-Innes A, Young E, Vasiljevic A, Rashid M. Air travelers' awareness of the preventability of otic barotrauma. J Laryngol Otol. 2014; 128(6): 494-8. Doi:10.1017/S 0022215114001145.

4. Sheikh S, Baig MA. Colonic barotrauma causing tension pneumoperitoneum following jet air insufflation to the rectum. Eurasian J Emerg Med. 2018; 17 (3): 133-5. Doi: 10. 5152/eajem.2018.07769.

5. Smith ME, Scoffings DJ, Tysome JR. Imaging of the Eustachian tube and its function: a systematic review. Neuroradiol. 2016; 58, 543-56. Doi: 10.1007/s00234016-1663-4. 
6. Fletc J. How to treat and prevent ear barotrauma [Internet]. 2018. Medical News Today [Cited 2019 July 11]. Available from: https://www.medicalnewstoday. com/articles/ 322215.php.

7. Ghosh S, Kumar V. Study of middle ear pressure in relation to eustachian tube patency. Ind J Aerospace Med. 2002; 46(2): 27-30.

8. Wang $M$, Han X, Fang $H, X u C$, Lin X, Xia S, Yu W, He J, Jiang $S$, Tao $H$. Impact of health education on knowledge and behaviors toward infectious diseases among students in Gansu Province, China. BioMed Res Int. 2018; 2018: 1-12. Doi: 10.1155/2018/6397340.

9. Wiredja D, Popovic V, Blackler A. A passengercentered model in assessing airport service performance. J Model Manage. 2019; 14(2): 492-520. Doi: 10.1108/JM2-10-2018-0171.

10. Sultani I, Khayat SK, Garout IR, Alahmad LS, Alzahrany AAA. The prevalence and risk factors of otic barotraumas among aircrew members. Int J Life Sci Pharma Res. 2019; 9(2): 24-30. Doi: 10.22376/ijpbs/Ipr.2019.9.2.P24-30.

11. Treece EW, Treece JW. Elements of research in nursing (3rd ed.). 1982; St. Louis, MO: Mosby.

12. Connelly LM. Pilot studies. Medsurg Nursing. 2008; 17(6): 411-12.

13. Wright T. Middle-ear pain and trauma during air travel. BMJ Clin Evid. 2015; 2015(1): 0501. PMID: 25599243.

14. Rehman CM, Zaheer S, Rizvi F, Afzal M. Frequency of ear problems associated with diving and their prevention in Pakistan. Pak Armed Forces Med J. 2010; 60(1): 135-9.

15. Soederberg MLM. Age differences in the effects of domain knowledge on reading efficiency. Psychol Aging. 2009; 24(1): 63-74. Doi:10.1037/a0014586.
16. Khan F, Ahmad N. Pneumoperitoneum following mechanical ventilation in a child. J Coll Phys Surg Pak. 2001; 11(8): 508-10.

17. McKercher B, Packer T, Yau M, Lam P. Travel Agents: facilitators or inhibitors of travel for people with disabilities? Tour Manag. 2003; 24 (4): 465-74.

18. Harackiewicz JM, Smith JL, Priniski SJ. Interest Matters: The importance of promoting interest in education. Policy Insights Behav Brain Sci. 2016; 3(2): 220-7. Doi:10.1177/2372732216655542.

19. Dickens GL, Ion R, Waters C, Atlantis E, Everett B. Mental health Nurses' attitudes, experience, and knowledge regarding routine physical healthcare: systematic, integrative review of studies involving 7,549 nurses working in mental health settings. BMC Nursing. 2019; 18(1): 1. Doi: 10.1186/s12912-0190339-x.

20. Obse A, Hailemariam D, Normand C. Knowledge of and preferences for health insurance among formal sector employees in Addis Ababa: a qualitative study. BMC Health Serv Res. 2015; 15: 318. Doi:10.1186/s12913-015-0988-8.

21. Stefanescu CD, Zainea V, Hainarosie R. Aerotitis media. Rev Air Force Aca. 2014; 3(27): 133-6.

22. Ayub F, Haider I, Saeed S, Murtaza B, Tariq, M. Shortterm outcomes in patients undergoing mechanical ventilation in a tertiary care centre in Sialkot. Pak Armed Forces Med J. 2018; 68(4): 1007-12.

23. El-Ghitany EM, Mohamed Abdelmohsen MA, Farghaly AG, Abd El-Gawwad ES, Abd El- Wahab EW. Travel health survey: risk perception, health-seeking behavior, and subjective evaluation of travel health services in Egypt. Int J Travel Med Glob Health.2018; 6(1): 16-24. Doi:10.15171/ijtmgh.2018.04.

24. Chen Q, Kong $Y$, Gao W, Mo L. Effects of socioeconomic status, parent-child relationship, and learning motivation on reading ability. Front Psychol. 2018; 9: 1297. Doi:10.3389/ fpsyg.2018.01297. 